\title{
Joodse religieuse uitbreiding in die Nuwe-Testamentiese tydvak: Was die Judaïsme 'n missionêre godsdiens? (Deel I)
}

A B du Toit

\section{ABSTRACT}

Jewish religious expansion in the New Testament era: Was Judaism a missionary religion? (Part I)

The dramatic increase in the Jewish population towards the end of the Second Temple period has prompted the theory that Judaism at that stage was an energetic missionary religion. But this phenomenon should rather be ascribed to a variety of factors. In this first article five of these factors are discussed: the Jewish attitude towards procreation, the fact of the Diaspora, forced proselytizing, intermarriage and the "conversion" of nonJewish slaves.

\section{INLEIDEND}

In enige diskussie rondom die mate waarin en die wyse waarop nie-Jode in die Tweede-Tempel tydvak, en in besonder in die Nuwe-Testamentiese periode, deur die Joodse godsdiens beïnvloed is, speel die indrukwekkende syfers wat vir die fisiese getalle van Jode teen die eerste eeu aangegee word, 'n belangrike rol. Die springende punt in hierdie verband is die aanname dat die groot getalle wat in die ou bronne vermeld word, onmoontlik die blote produk van natuurlike aanwas kon gewees het. Hierdie getalle, so lui die argument, moet noodwendig groot getalle proseliete insluit. In sy beroemde werk oor die uitbreiding van die Christendom in die eerste drie eeue verklaar Adolf von Harnack byvoorbeeld: “...aus der Fruchtbarkeit der Juden allein erklärt sich die hohe Zahl der Diasporajuden schlechterdings nicht. Man wird anzunehmen haben dass sehr zahlreiche 'Heiden'... scharenweise zur Religion Jahves übergegangen sind" 1 . En, so gaan die argument voort, hierdie groot "skares" was slegs moontlik indien die Jodedom 'n doelbewuste en energieke missionêre strategie gevolg het. As Nuwe-Testamentiese kroongetuie in hierdie verband word Matteus 23:15 ingeroep: "Wee julle, skrifgeleerdes en Fariseërs, huigelaars! Julle gaan rond oor see en land om 
een proseliet te maak; en wanneer hy dit geword het, maak julle hom 'n kind van die hel, twee maal erger as julleself".

In hierdie en 'n opvolgartikel word eerstens 'n aantal belangrike definisies en verdere omskrywings aangebied. Daarna gee ons aandag aan die getalleskattings van die destydse Jodedom; derdens word gevra na die faktore wat hierdie getalleaanwas bevorder of kon bevorder het; vierdens volg ' $n$ bespreking van die standpunt dat hierdie indrukwekkende getalle in 'n belangrike mate aan Joodse sendingywer te danke was, tesame met 'n aantal ander ondersteunende argumente; vyfdens word 'n aantal kontraargumente onder die loep geneem; en ten slotte volg 'n eie standpuntinname.

\section{2 'N PAAR DEFINISIES EN VERDERE OMSKRYWINGS}

Reeds McKnight het gekla oor die wollerigheid waarmee terme in verband met ons onderwerp gebruik word' ${ }^{2}$. Om hierdie rede gee ek nou eers 'n omskrywing van sekere sleutelbegrippe wat gebruik gaan word, asook enkele breër verduidelikings.

\subsection{Die begrippe "sending" en "missionêre godsdiens"}

Die begrip "sending" word in hierdie artikel gebruik in die sin van 'n doelbewuste, aktiewe uitreiking na ongelowiges of persone van 'n ander godsdiens met die doel om hulle deur 'n oortuigings-, 'n harts- en 'n lewensverandering, dit wil sê deur "bekering", lede van jou eie godsdiensgroep te maak. Agter hierdie missionêre aksie lê enersyds die oortuiging dat jou groep se geloofsaanspraak vir alle mense geld ${ }^{3}$ en andersyds dat hierdie geloofsoortuigings eksklusief is, dit wil sê dat 'n persoon nie terselfdertyd aan 'n ander godsdiensgroep kan behoort nie.

Dienooreenkomstig bedoel ek met 'n "missionêre godsdiens" een wat kragtens sy eie intrinsieke oortuigings, waaronder byvoorbeeld dié aangaande God as universele Skepper met 'n universele aanspraak, doelbewus en aktief met sy boodskap na ander groepe uitbeweeg om hulle vir die eie godsdiens te wen.

\subsection{Indirekte sending}

Hierdie term word gebruik bloot by gebrek aan 'n beter een. Hiermee word bedoel die aantrekkingskrag wat 'n bepaalde godsdiens vanweë sy intrinsieke aard en beoefening op ongelowiges of andersgelowiges uitoefen. 
Hierdie indirekte sending kan geskied in gevalle waar die betrokke godsdiensgroep dit nie as deel van sy roeping beskou om aktief uit te beweeg nie, maar ook in gevalle waar dit 'n sendingbewussyn en sendingaksie wat wel bestaan, onderskraag. Waar sending soos hierbo gedefinieer 'n sterk sentrifugale karakter besit, besit hierdie "werwingskrag" sterk sentripetale elemente.

\subsection{Die benaming "proseliet"}

Nie-Jode kon in verskillende grade van verbondenheid tot die Joodse volk staan 4 . McKnight onderskei vyf sulke "levels of adherence" 5 . Dit is in elk geval makliker om die twee uiterstes op hierdie breë spektrum te bepaal as die variasies tussen-in. Op die een uiterste was daar diegene wat wel 'n geringe mate van gehegtheid aan die Joodse geloof getoon het, maar nog nie hulle heidense godsdienstige verbondenhede afgesweer het nie. Tertullianus verwys byvoorbeeld na heidene wat nog hulle eie gode vereer het, maar terselfdertyd sekere Joodse voorskrifte eerbiedig het (Ad nat I 13:34). Op die ander uiterste punt was daar diegene wat hulle sonder voorbehoud in alle opsigte by die Joodse geloof geskaar het, naamlik die proseliete. In hierdie konteks word die term "proseliet" gebruik in die tegniese sin van 'n nie-Jood wat al die geloofsoortuigings en verpligtinge van die Judaïsme sy eie gemaak het en deur voldoening aan die drie vereistes van besnydenis (in die geval van mans), rituele wassing (die sogenaamde proselietedoop) en 'n tempeloffer (indien moontlik) 'n volle lid van die Joodse gemeenskap geword het en wel in religieuse sowel as sosiale opsig6. Dat die proseliete, afgesien van enkele geringe voorbehoude ${ }^{7}$, wesenlik as volle lede van die Joodse volk beskou is, blyk uit inskripsies uit die Joodse katakombes te Rome, waar hulle, anders as die sogenaamde "Godvresendes", sonder meer tussen die Jode begrawe is.

Die Griekse woord prosēlutos is die gebruiklike vertaalekwivalent vir die Hebreeuse גִֵ Albei terme is in die Septuagint en die Hebreeuse Bybel oorspronklik gebruik vir ' $n$ vreemdeling wat in die Joodse gebied vertoef, maar het later die reeds-genoemde tegnies-religieuse betekenis verkry8. Van die oudste voorkomste van hierdie tegniese gebruik van /גֵ:prosēlutos kry ons in Tobit 1:8 en CD 6:219. Alhoewel Filo an ander terme voorkeur gee, gebruik hy tog ook prosēlutos in hierdie betekenis. In Spec Leg 1:51 omskryf hy prosēlutoi vir sy nie-Joodse lesers soos volg: toutous de kalei prosēlutous apo tou proselēluthenai kainē kai filotheō politeia (Hy noem hulle proseliete, omdat hulle aangesluit het by ' $\mathrm{n}$ nuwe en Godliefhebbende burgerskap = die Judaïsme). Hierdie tegniese term, 
wat in die Rabbynse literatuur 'n staande uitdrukking geword het, kry ons ook op inskripsies ${ }^{10}$, waaronder die opspraakwekkende marmersteen wat in 1976 te Afrodisias ontdek is ${ }^{11}$. In die Nuwe Testament kom dit voor in Matteus 23:15, asook in Handelinge 2:11 en 6:5, terwyl die gebruik in Handelinge 13:43 onduidelik is.

\subsection{Godvresendes}

Die benamings "Godvresendes" (theofoboumenoi; ook foboumenoi ton theon) of "Godvereerders" (theosebomenoi, met theosebeis as variant; ook sebomenoi ton theon) het nooit dieselfde tegniese konnotasie verkry as "proseliete" nie. Dit is byvoorbeeld ook vir Jode gebruik. In semi-tegniese sin het dit egter gedien as sambreelterm vir 'n breedgeskakeerde groep heidene wat 'n wisselende mate van simpatie met die Joodse godsdiens getoon het, maar hulle nog nie in so 'n mate met die Judaïsme vereenselwig het dat hulle proseliete geword het nie. Die verskil tussen proseliet en Godvresende was duidelik in die sin dat die besnydenis en die daarmee gepaardgaande handelinge definitiewe grensmerkers was wat eersgenoemde van laasgenoemde onderskei het. Dit was egter na die kant van die heidendom waar daar 'n grys gebied gelê het. Selfs die eksklusiewe verering van die een ware God het nie altyd vir die laasgenoemdes as duidelike identiteitsmerker gegeld nie, aangesien sommige simpatiseerders, soos ons hierbo gesien het, nog wydsbeen oor die twee wêrelde van monoteïsme en heidendom gestaan het ${ }^{12}$. Afgesien van die bywoning van sinagogedienste, die verering van die een, ware God en die aanvaarding van ander basiese aspekte van die Joodse geloofsoortuigings, het sake soos die viering van die Sabbat en die nakoming van verskillende Joodse reinheidsbepalings, veral kosvoorskrifte (bv die onthouding van varkvleis), die graad van individuele Godvresendes se verbondenheid aan die Jodedom bepaal. Ten spyte van die vaagheid van die term "Godvresende" word dit tog deur die meeste wetenskaplikes aanvaar as 'n semi-tegniese dekwoord vir 'n bepaalde groep wat enersyds nog nie proseliete was nie, maar andersyds ook nie meer heeltemal heidene nie.

Hierdie standpunt was nietemin vir 'n lang tyd die onderwerp van 'n hewige debat ${ }^{13}$. Die feit dat Lukas telkens van Godvresendes of Godvereerders praat en hulle duidelik van die Jode onderskei (Hd 10:2, 22, 35; $13: 16,26,43,50 ; 16: 14 ; 17: 4,17 ; 18: 7)$ was volgens Kraabel geensins 'n betroubare historiese aanduiding nie, maar 'n literêre skepping van Lukas ${ }^{14}$. Hy praat in 'n oomblik van wetenskaplike voortvarendheid selfs van die "verdwyning" van die Godvresendes ${ }^{15}$. Ook Murphy-O'Connor het 
sy bedenkinge...16. In hierdie verband kon die vroeër bekende inskripsies ook nie besliste uitsluitsel gee nie, alhoewel dié van Delirer naby Filadelfia in Lidië en veral die een van die teater te Milete tog enigsins sterker in die rigting van 'n afsonderlike nie-Joodse groep wys ${ }^{17}$. Die bestaande onsekerheid is egter uit die weg geruim met die reedsvermelde ontdekking van die marmersteen in Afrodisias. Op hierdie inskripsie word die name vermeld van 125 weldoeners wat bygedra het tot 'n Joodse liefdadigheidsinstelling, vermoedelik 'n soort sopkombuis waar behoeftiges vir 'n maaltyd kon gaan aanklop. Drie groepe kan hier duidelik onderskei word: 68 Jode, 3 proseliete en 54 Godvresendes. Interessant genoeg is daar 9 raadslede van die stad onder hierdie laaste groep. Die lys van groot aantal Godvresendes bewys nie net die invloedrykheid van die Joodse gemeenskap in Afrodisias nie, maar ook watter groot getal Godvresendes by die sinagoge aldaar betrokke was (net die weldoeners onder hulle word hier genoem). Verder toon dit dat 'n aansienlike deel van hierdie Godvresendes tot die hoër sosiale klas behoort het. Alhoewel hierdie gegewens nie heeltemal sonder probleme is nie, en Kraabel en Murphy-O'Conner hierdie getuienis nog steeds nie as beslissend beskou nie ${ }^{18}$, kan die bestaan van die Godvresendes as enigsins vae, maar tog identifiseerbare groep moeilik langer ontken word ${ }^{19}$.

\section{DIE DEMOGRAFIESE GETUIENIS: GETALLESKATTINGS}

Die Joodse Diaspora, wat reeds begin het met die Assiriese en Babiloniese wegvoerings waarvan ons in die $\mathrm{Ou}$ Testament lees, het steeds in momentum toegeneem. Teen die eerste eeu na Christus het dit oor groot dele van die destyds bekende wêreld gestrek. Josefus (Antiq. XIV 7:2) haal Strabo hieroor soos volg aan: "Hierdie volk het reeds sy weg gevind tot elke stad en dit is nie maklik om 'n plek in die bewoonde wêreld te kry tot waar hierdie nasie nog nie deurgedring het en wat nog hulle mag ervaar het nie". Hierby sluit 'n opmerking van Filo aan wat dit stel dat die Jode so baie is "dat geen enkele land hulle kan bevat nie en daarom het hulle hulleself in talle van die mees welvarende stede van Europa en Asië gevestig" (Flac. 45-46). En dieselfde skrywer sê in sy Legatio ad Gaium 214 aangaande die Joodse volk dat dit "versprei is oor al die kontinente en eilande, sodat dit lyk of hulle nie baie minder is as die inheemse inwoners nie". Hierdie stellings is sekerlik oordrewe, maar dui nietemin op die aansienlike getalsterkte en verspreidheid van die Jodedom oor die ganse kom rondom die Middellandse See, met uitlopers wat nog veel verder strek. 
Die woord "skatting" ten opsigte van die getalsterkte van die destydse Jodedom is in die opskrif hierbo doelbewus gebruik omdat 'n noukeurige berekening heeltemal buite die kwessie is. Die probleem lê enersyds by die onvolledigheid van ons beskikbare bronne, andersyds by die onnoukeurigheid van hierdie bronne. As gevolg van destydse omstandighede was presiese statistieke net eenvoudig nie beskikbaar nie. En waar getalle wel aangedui is, was dit dikwels vir propagandadoeleindes gemanipuleer. As 'n mens Josefus byvoorbeeld sou glo, moes daar sowat 3 miljoen Joodse feesgangers in die sestigerjare van die eerste eeu aan die Paasfees in Jerusalem deelgeneem het (Bell. Jud. II 14:3). Logisties is hierdie syfer heeltemal onmoontlik. Dit is veelbetekenend dat Joachim Jeremias hierdie selfde getal in sy Jerusalem zur Zeit Jesu aanvanklik op slegs 125,000 bereken het en dit in die derde uitgawe nog verder afgebring het $^{20 !}$

Skattings vir die totale aantal Jode in die Romeinse Ryk gedurende die eerste eeu van ons Christelike jaartelling wissel tussen 2 miljoen en meer as 8 miljoen $^{21}$. Harnack het die getal Jode in Egipte op sowat 1 miljoen, in Sirië op ietwat meer, in Palestina op 500,000 en in die oorblywende gebiede, waaronder Klein-Asië, die Griekse gebiede, Mesopotamië, Rome, Italië, Afrika, Gallië en Spanje, op $1 \frac{1 / 2}{2}$ miljoen geskat. Dit het die totaal op sowat $4-4 \frac{1}{2}$ miljoen vir die hele Romeinse Ryk gebring. Baron ${ }^{22}$ se skatting is aansienlik hoër. Hy plaas die Joodse totaal op 8 miljoen, waarvan 3 miljoen in Palestina. Van der Horst se syfer is $1 \frac{1}{2}$ miljoen tot 2 miljoen vir Palestina en 3-31/2 miljoen vir die Diaspora. Opvallend is in hierdie verband veral twee sake: Eerstens dat die getal Jode buite Palestina reeds die aantal in Palestina by verre oortref het. Volgens Harnack was daar agt keer meer Jode in die buiteland as in Palestina self. Sy berekening van die Jode in Palestina self was egter vermoedelik te laag. Die tweede opvallende feit is dat die Jode op hierdie stadium reeds 'n nie onaansienlike persentasie van die totale aantal inwoners van die Romeinse Ryk moes uitgemaak het. As ons Harnack se berekenings as basis neem hy meen dat die totale bevolking van die Romeinse Ryk met die dood van Augustus ongeveer 54-60 miljoen was - moes dit reeds 'n indrukwekkende 7\% beloop het! Ook Tcherikover $^{23}$ skat hierdie verhouding op 7\%.

Watter van die bostaande syfers ook al die naaste aan korrek mag wees - een feit staan buite kyf: dat die totaal van die Joodse bevolking op hierdie stadium verrassend hoog was. Die vraag is nou watter faktore hiertoe kon bygedra het. Naas die positiewe kragte was daar egter ook kontra-kragte wat 'n rol gespeel het. Waar toepaslik sal ook aan hierdie kontra-kragte aandag gegee moet word. 


\section{FAKTORE WAT DIE JOODSE GETALSTERKE BEÏNVLOED HET}

\subsection{Die Joodse klem op prokreasie}

Dit was deel van die Joodse tradisie om kinders as 'n seën van die Here te beskou. Sowel die aantal as die oorlewing van kinders was van belang. Kontrasepsie, aborsie en die verwerping van kinders na geboorte was verbode $^{24}$ - dinge wat heel dikwels onder nie-Jode voorgekom het. Dit spreek vanself dat hierdie etos besonderlik bevorderlik was vir bevolkingstoename.

\subsection{Die feit van die Diaspora}

Die verowerings van Aleksander die Grote en die grootskaalse oopstellings en gelykmakingsproses wat hy en sy epigone gevolg het, het meegebring dat kulturele, politieke en nasionale grense nooit weer so absoluut sou wees as vroeër nie. Die Helleniseringsproses, in besonder die groei van Grieks tot algemene taal, het kommunikasie geweldig vergemaklik. Internasionale verkeer, handel en onderhandelinge het 'n mate van ekonomiese, kulturele, filosofiese en religieuse blootstelling en wisselwerking meegebring. Die koms van die Romeinse Ryk en die stabiliteit wat dit meegebring het, het hierdie oopstelling van horisonne in die ganse gebied rondom die Middellandse Seebekken verder bevorder.

Vir die Jode van Palestina, wat lank reeds te veel geword het vir die beperkte infrastruktuur en hoofsaaklik agrariese ekonomie 25 van hulle moederland, het hierdie situasie nuwe bestaansmoontlikhede gebied. Daarom is dit geen wonder dat soveel hulle heil elders gaan soek het en dat die aantal Jode in die Diaspora geweldig vermeerder het nie. Ook die gewelddadige wegvoeringsbeleid van seëvierende magte oor baie eeue het die Diaspora versterk. Tog sou die voortgaande proses van vrywillige verhuising die grootste bydrae tot die Diaspora lewer.

Hierdie nuwe situasie het vir die Jode sowel as vir hulle heidense omgewing belangrike implikasies gehad. Die geografiese verspreiding van die Jode het meegebring dat veel meer nie-Jode as voorheen in meerdere of mindere mate met die Joodse geloof en leefwyse kennis gemaak en binne bereik van die Joodse invloedsfeer gekom het. Maar omgekeerd het die Jode ook op 'n veel drastieser wyse as voorheen binne die nie-Joodse invloedsfeer gekom. Kultureel was hulle veel sterker as voorheen aan die 
Hellenistiese kultuur, en in besonder aan die Griekse taal, blootgestel en het Grieks weldra die gebruikstaal van hierdie Jode geword. Die Griekse denke het ongemerk die Joodse denkpatrone begin beïnvloed. Op religieuse gebied moes die Jood hom nie alleen ten opsigte van sy eie geloofsoortuigings en lewenskodes opnuut verantwoord nie, maar het hy steeds meer die noodsaaklikheid ervaar om sy eiesoortige geloof en leefwyse aan die nie-Joodse omgewing te verduidelik. Daarbenewens het die kontak met nieJode die standpunte en denke van Jode in die Diaspora op meer as een wyse verruim. Op sekere van hierdie fasette sal ek verderaan terugkom. Dit sou natuurlik foutief wees om te meen dat die Jode eers in die Diaspora met nie-Joodse idees in kontak gekom het. Ook in Palestina self is hulle daagliks met aspekte van die Hellenistiese kultuur en heidense godsdienste gekonfronteer ${ }^{26}$. Begryplikerwys was die intensiteit van hierdie kontak in die Diaspora egter veel sterker.

\subsection{Gewelddadige proselietmaking}

In Palestina self het ons meer as een geval van geforseerde "bekerings" gekry. Na die dood van die Siriese Antiogus VII in 129 v C het Hirkanus die regeringstyd van eersgenoemde se swak opvolger gebruik om die Joodse gebied uit te brei. Onder meer het hy die Idumese dorpe Adora en Marissa ten suide van Judea verower en die besnydenis en die Joodse geloof op die Idumeërs afgedwing (Josefus Antiq XIII 9:1; Bell Jud I 2:6). Op hierdie manier het die latere Herodeshuis deel van die Jodedom geword, alhoewel hulle steeds deur die Joodse aristokrasie smalend as "half-Jode" bestempel is. Op sy beurt het Aristobolus I (104-103 v C) die Iturieërs in die noorde verslaan en die besnydenis op hulle afgedwing. Op hierdie wyse is die oorgrote deel van Galilea gejudaïseer (Josefus Antiq XIII 11:3). Die energieke Aleksander Janneus het die verowerings van Hirkanus in die Oos-Jordaangebied verder voortgesit en ten minste 'n gedeelte van hierdie bevolking verjoods (Josefus Antiq XIII 15:4).

\subsection{Ondertrouing}

In die Persiese tydvak het Esra en Nehemia ondertrouing tussen Jood en nie-Jood nog met radikale maatreëls teengestaan. In reaksie hierop het die leidende priesters die konsep ontwikkel dat nie-Jode wat die nodige toelatingsvereistes nakom, wel tot die Joodse gemeenskap toegelaat kon word. Hierdie maatreël, wat oorspronklik uit reaksie op probleme rondom ondertrouing afkomstig was, het volgens Morton Smith in werklikheid die 
hele karakter van die Jodedom verander. Dit het, aldus Smith, van die Judaïsme 'n wêreldgodsdiens gemaak, "capable of indefinite extension by conversion of all peoples" 27 . Voortaan sou alle Jode, mans sowel as vroue, van hulle nie-Joodse huweliksmaats verwag om die Judaïsme te aanvaar voordat die huwelik gesluit kon word (vgl Josefus Antiq XX 7:1). Selfs iemand soos Herodes die Grote, wat die Joodse voorskrifte nie juis danig ernstig nagekom het nie, het daarop aangedring dat die Nabateër Sileus, wat met sy suster Salome wou trou, eers die Joodse gebruike moes aanvaar met die gevolg dat die huweliksplanne skipbreuk gely het (Josefus Antiq XIV 7:6).

\subsection{Verjoodsing van slawe}

In die eerste eeu was daar 'n groot aantal slawe in Joodse huishoudings, waarvan die meerderheid, indien nie almal nie ${ }^{28}$, van nie-Joodse herkoms was. Omdat slawe as deel van die huishouding beskou is, het hulle groot druk ervaar om die Joodse geloof aan te neem en het verreweg die meeste dit dan ook gedoen ${ }^{29}$. Hoe diep hierdie "bekering" gegaan het, is natuurlik 'n ander vraag. Ons weet egter van slawe wat allerlei religieuse funksies namens hulle base vervul het en wat later selfs met lede van die huisgesin getroud is ${ }^{30}$.

In die tweede aflewering van hierdie artikel word nog 'n aantal faktore bespreek en die hipotese van 'n volskaalse Joodse sendingbeweging aan die orde gestel.

\section{NOTAS:}

1 A von Harnack, Die Mission und Ausbreitung des Christentums in den ersten drei Jahrhunderten, Leipzig ${ }^{4} 1924,13$.

2 S McKnight, A light among the gentiles. Jewish missionary activity in the second temple period, Minneapolis 1991, 4.

3 In sy "interim definisie" van sending wys D Bosch daarop dat missionêre godsdienste almal intrinsiek missionêr is omdat hulle uitgaan van die bekendmaking van ' $n$ finale waarheid wat vir alle mense van lewensbelang is. Kyk sy Transforming mission. Paradigm shifts in theology of mission (American Society of Missiology Series 16), Maryknoll, New York 1991, 8.

4 'n Goeie bespreking hiervan by E Schürer, The history of the Jewish people in the age of Jesus Christ III/1 (ed by G Vermes, F Millar \& M Goodman), Edinburg rev ed1986, 164-165. 
$5 \quad A w, 90-101$.

6 Die herhaalde beklemtoning van K G Kuhn, art proselutos, ThWNT VI, 730737 , dat die term proseliet 'n suiwer religieuse begrip was, skep 'n verkeerde indruk. Die proseliet is ook in die Joodse volksverband opgeneem.

7. Vergelyk Schürer, $a$ w, III/2, 175-176; M Stern, Aspects of Jewish society: the priesthood and other classes, in: S Safrai \& M Stern (eds), The Jewish people in the first century I/2 (CRINT) Assen-Amsterdam 1976, 623-624.

8 'n Bondige oorsig oor die geskiedenis van prosêlutos en belangrike literatuur kan gerieflikheidshalwe gekry word by Schürer, $a$ w III/1, 169-170; 'n breedvoeriger bespreking by K G Kuhn, art prosēlutos, ThWNT VI.

$9 \quad$ Vergelyk Kuhn, a $w, 735-736$.

10 Hierdie getuienis is egter nie so volop as wat 'n mens sou verwag nie. Vergelyk ten opsigte van Rome byvoorbeeld McKnight, $a w, 74$.

11 Drie proseliete word by name genoem. P W van der Horst, Essays on the Jewish world of early Christianity (NTOA 14), Göttingen 1990, 161-181, gee 'n interessante bespreking en evaluering van hierdie inskripsie.

12 Kyk by J Reynolds \& R Tannenbaum, Jews and Godfearers at Aphrodisias, Cambridge 1987, 48-66 wat 'n uitvoerige definisie van die Godvresendes gee.

13 Kyk byvoorbeeld by Schürer, $a w, \mathrm{III} / 1,166$.

14 A $\mathrm{T}$ Kraabel, "Immigrants, exiles, expatriates, and missionaries", in: L Bormann, K Del Tredici \& A Standhartinger (eds), Religious propaganda and missionary competition in the New Testament world. Essays honoring Dieter Georgi, Leiden-New York-Köln 1994, 81, 85.

15 In sy artikel “The disappearance of the 'God-fearers'", Numen 28 (1981), 113126. In 'n ander artikel wat hy saam met MacLennan skryf, verklaar hy in verband met hierdie "device" van Lukas: "It is a tribute to Luke's dramatic ability that the God-fearers have become so alive for the later church" - A T Kraabel \& R S MacLennan, "The God-fearers - a literary and theological invention", in: J E Overman \& R S MacLennan (eds), Diaspora Jews and Judiasm. Essays in honor of, and in dialogue with, A. Thomas Kraabel (Diaspora Jews and Judaism 41), Atlanta 1992, 141; oorspronklik gepubliseer in BAR 12 (1986), 47-53.

16 Murphy-O'Connor, “Lots of God-fearers? Theosebeis in the Aphrodisias inscription", $R B 99$ (1992), 418-424. 
17 Schürer, $a w, \mathrm{III} / 1,167$.

18 Kraabel, Immigrants, 80-85; Murphy-O'Connor, $a$ w.

19 Ek kan akkoord gaan met F Millar wat in die nuwe Schürer, $a w \mathrm{III} / 1,166$, met goeie reg verklaar: "It would be difficult to imagine clearer evidence that theosebeis could be categorized as a formal group attached to a Jewish community, and distinguished both from Jews and from full proselytes. Vergelyk verder Van der Horst, a w, 16; T Rajak, "The Jewish community and its boundaries", in: J Lieu, J North \& T Rajak (eds), The Jews among pagans and Christians in the Roman Empire, London and New York 1992, 20-21; L H Feldman, Jew and gentile in the ancient world. Attitudes and interactions from Alexander to Justinian, Princeton 1992, 367-368.

20 J Jeremias, Jerusalem zur Zeit Jesu, Göttingen ${ }^{31962, ~ 89-98 . ~}$

$21 \quad$ Kyk P W van der Horst, $a$ w, 1990, 170-171.

22 S W Baron, A social and religious history. of the Jews I, Philadelphia-New York 21952, 170.

23 V Tcherikover, Hellenistic civilization and the Jews, Philadelphia 1961, 292293.

$24 \quad$ M Stern, $a w, 750$.

25 S Applebaum, "Economic life in Palestine", in: S Safrai \& M Stern (eds), $a w$ $\mathrm{I} / 2,631-700$.

26 Vir die Griekse taal vergelyk G Mussies, "Greek in Palestine and the Diaspora", in: S Safrai \& M Stern (eds), $a w, 1 / 2,1040-1064$; vir nie-Joodse godsdienste, D Flusser, "Paganism in Palestine", in: S Safrai \& M Stern (eds), a $w, \mathrm{I} / 2,1065-1100$.

27 M Smith, "Jewish religion in the Persian period", in: W D Davies \& L Finkelstein (eds), The Cambridge history of Judaism I, New York ${ }^{2} 1988,269$.

28 S Safrai, "Home and family", in: S Safrai \& M Stern (eds), a w, I/2, (728-792) 751, meen selfs dat daar op hierdie stadium geen Joodse slawe meer in Palestyns-Joodse huishoudings was nie.

29 M Stern, “Aspects of Jewish society", in: S Safrai \& M Stern (eds), $a w 1 / 2$, (561-630) 628-630.

30 Vergelyk Safrai, idem. 